\title{
65742
}

\section{AIRCRAFT MEASUREMENTS \\ OF MICROWAVE EMISSION FROM ARCTIC SEA ICE}
N72-10276 (NASA-TM-X-65742) AIRCRAFT MEASUREMENTS OF NICROWAVE EMISSION FRON ARCTIC SEA ICE T.
Unclas Wilheit, et al (NASA) Sep. 197125 p CSCL $08 \mathrm{~K}$ 08701

\section{T. WILHEIT \\ J. BLINN \\ W. CAMPBELL \\ A. EDGERTON \\ W. NORDBERG}

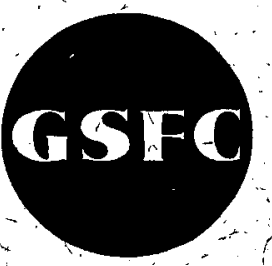

SEPTEMBER 1971

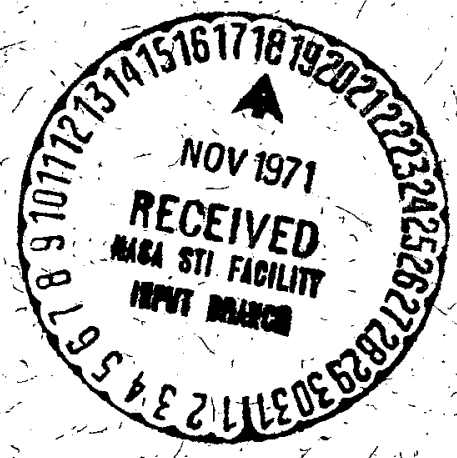

NATIONAL TECHNICAL INFORMATION SERVICE Springfield, Va. 22151

GODDARD SPACE FLIGHT CENTER

GREENBELT, MARYLAND
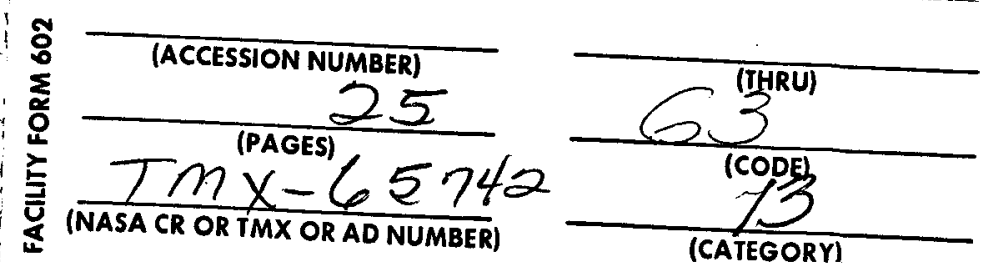


\title{
AIRCRAFT MEASUREMENTS OF MICROWAVE \\ EMISSION FROM ARCTIC SEA ICE
}

T. Wilheit

NASA/Goddard Space Flight Center

\author{
J. Blinn \\ Jet Propulsion Laboratory \\ W. Campbell \\ U. S. Geological Survey \\ A. Edgerton \\ Aerojet-General Corporation \\ W. Nordberg \\ NASA/Goddard Space Flight Center
}

September 1971

GODDARD SPACE FLIGHT CENTER

Greenbelt, Maryland 
PRECEDING PAGE BLANK NOT FLMY

\title{
AIRCRAFT MEASUREMENTS OF MICROWAVE
}

\author{
EMISSION FROM ARCTIC SEA ICE
}

\begin{abstract}
Measurements of the microwave emission from Arctic Sea ice were made with aircraft at 8 wavelengths ranging from $0.510 \mathrm{~cm}$ to $2.81 \mathrm{~cm}$. The expected contrast in emissivities between ice and water was observed at all wavelengths. Distributions of sea ice and open water were mapped from altitudes up to $11 \mathrm{~km}$ in the presence of dense cloud cover.

Different forms of ice also exhibited strong contrasts in emissivity. Emissivity differences of up to 0.2 were observed between two types of ice at 0.811 cm wavelength. The higher emissivity ice type is tentatively identified as having been formed more recently than the lower emissivity ice.
\end{abstract}


CONTENTS

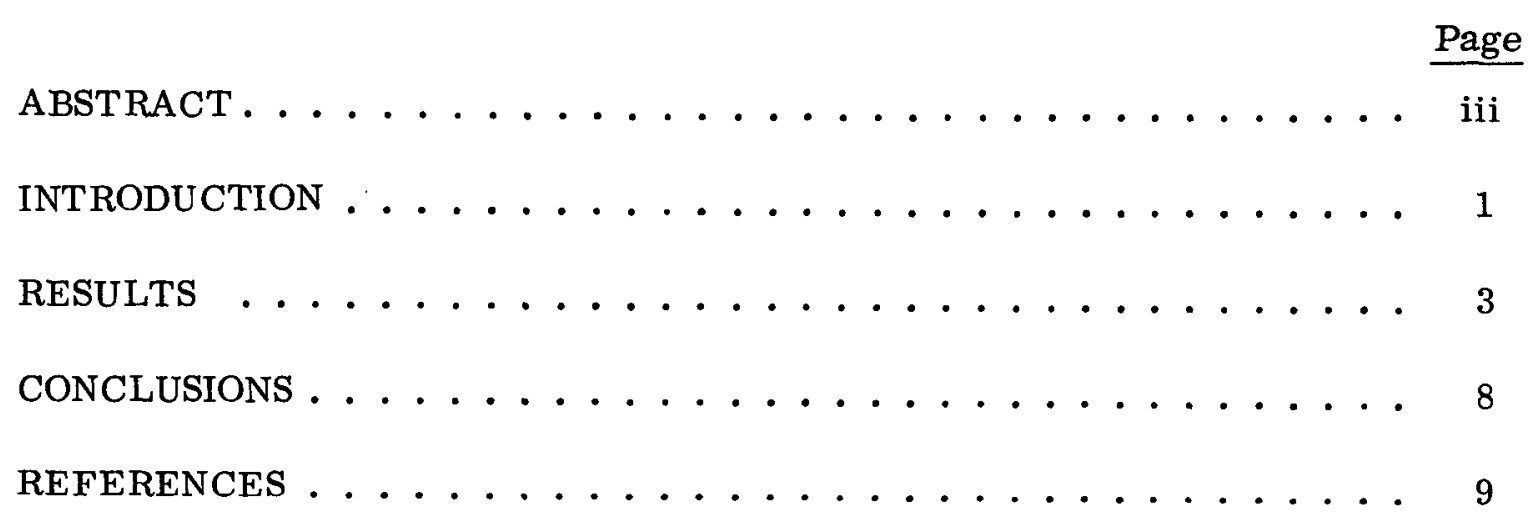




\section{ILLUSTRATIONS}

$\underline{\text { Figure }}$

$\underline{\text { Page }}$

1 False color $1.55 \mathrm{~cm}$ Microwave Image of Barrow, Alaska area ....................... 10

$2 \quad$ Map of a portion of the 1967 flight path . . . . . . . 12

3 False color $1.55 \mathrm{~cm}$ Microwave Image of Arctic Sea Ice $280 \mathrm{~km}$ North of Barrow, Alaska ............ 14

4 Infrared ektrachrome photomosaic of Arctic Sea Ice $280 \mathrm{~km}$ North of Barrow, Alaska . . . . . . . . . 16

$5 \quad$ Laser geodolite profile of Arctic Sea Ice $280 \mathrm{~km}$ North

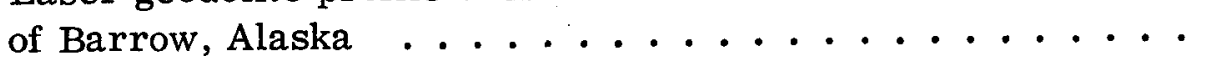

6 Microwave brightness temperature record for Arctic Sea Ice $280 \mathrm{~km}$ North of Barrow, Alaska .......... 18

$7 \quad$ Calculated zenith brightness temperature for four different cloud models with indicated liquid water content . . . . . 19

8 Observed emissivity spectrum of "old" and "new" ice . . . . . 20 
TABLES

Table

$\underline{\text { Page }}$

1 Microwave Radiometers Flown on 1967 and 1970

CV-990 Missions ................. 2

2 Confirmation of Sky Brightness Model and Radio-

meter Calibration ................ 7 


\section{AIRCRAFT MEASUREMENTS OF MICROWAVE EMISSION FROM ARCTIC SEA ICE}

\section{INTRODUCTION}

Recent studies (Badgley, 1966) of the ice covered oceans have suggested that the heat flux per unit area to the atmosphere is at least two orders of magnitude greater from exposed water than through sea ice. Further studies (Wittmann and Schule, 1967) indicate that at any time of the year as much as $10 \%$ of the Arctic Ocean may be open water, existing as polynyas (large cracks) and leads (small cracks) within the dynamically active ice canopy. Hence the heat flux of ice covered oceans, which comprise approximately $12 \%$ of the total ocean area of the Earth, is essentially determined by the formation and movement of polynyas

and leads. Synoptic mapping of open water in the polar ice canopy should, therefore, provide significant information on the energy budget at the atmospheresurface interface and on the deformation of the ice pack.

Because of the marked contrast between the microwave emissivities for ice $(0.8$ to 1.0$)$ and water $(0.4$ to 0.5$)$, microwave radiometry offers a unique method of providing all-weather, high contrast mapping of polynyas and leads. The method's primary limitation is the spatial resolution of the radiometer antenna. This paper reports the results of microwave radiation measurements over ice and water made on May 31, 1967 and June 11, 1970 with the NASA Convair 990 airborne observatory over the Arctic Sea north of Point Barrow, Alaska. The purpose of these measurements was to support future satellite experiments by (1) demonstrating the feasibility of mapping the size and distribution of polynyas and leads in the polar ice canopy and (2) determining the extent to which different types of sea ice are distinguishable on the basis of microwave emission. The results were positive.

The complement of microwave radiometers flown on the two missions is listed in Table I. The electrically scanned radiometer operating at $19.35 \mathrm{GHz}$ was the sole microwave radiometer on the 1967 mission, and the only one on either mission capable of producing images of the received radiation. The instrument performance and previous measurements of sea surface emissions with this instrument have been reported by Oister and Falco (1967) and Nordberg et al. (1967) respectively. Nine nonscanning microwave radiometers were added for the 1970 flights including the pilot model of a five channel microwave spectrometer to be flown on the Nimbus satellite and other instruments supplied by the Jet Propulsion Laboratory and the. Aerojet General Corp. Preliminary results on sounding the atmosphere with the five channel Nimbus pilot model were described by Rosenkranz (1971). The fields of view, pointing angles and other relevant instrument parameters for each radiometer are also contained in Table I. Ice and sea surface temperatures were measured with infrared 
Table I

Microwave Radiometers Flown on 1967 and 1970 CV-990 Missions

\begin{tabular}{|l|l|l|l|c|c|c|c|c|c|}
\hline Frequency & Wavelength & Flights & $\begin{array}{c}\text { Beam } \\
\text { Scan }\end{array}$ & $\begin{array}{c}\text { Pointing } \\
\text { Angle } \\
\text { (Relative } \\
\text { to Nadir) }\end{array}$ & $\begin{array}{c}3 \mathrm{DB} \\
\text { Beam- } \\
\text { width }\end{array}$ & $\begin{array}{c}\text { RMS } \\
\text { Temp. } \\
\text { Sens. }\end{array}$ & $\begin{array}{c}\text { Inte- } \\
\text { gration } \\
\text { Time }\end{array}$ & $\begin{array}{c}\text { Polari- } \\
\text { zation }\end{array}$ & $\begin{array}{c}\text { Sponsoring } \\
\text { Organization }\end{array}$ \\
\hline $19.35 \mathrm{GHz}$ & $1.55 \mathrm{~cm}$ & $167 \& 170$ & Yes & $\pm 50^{\circ}$ & $2.8^{\circ}$ & $1.4^{\circ} \mathrm{K}$ & $0.025 \mathrm{~S}$ & Single & GSFC \\
$22.235 \mathrm{GHz}$ & $1.35 \mathrm{~cm}$ & 1970 & No & $0^{\circ}$ & $10^{\circ}$ & $0.3^{\circ} \mathrm{K}$ & $2 \mathrm{~S}$ & Single & $\mathrm{MIT} / \mathrm{JPL}$ \\
$31.4 \mathrm{GHz}$ & $0.955 \mathrm{~cm}$ & 1970 & No & $0^{\circ}$ & $10^{\circ}$ & $0.4^{\circ} \mathrm{K}$ & $2 \mathrm{~S}$ & Single & $\mathrm{MIT} / \mathrm{JPL}$ \\
$53.65 \mathrm{GHz}$ & $0.559 \mathrm{~cm}$ & 1970 & No & $0^{\circ}$ & $10^{\circ}$ & $1.2^{\circ} \mathrm{K}$ & $2 \mathrm{~S}$ & Single & $\mathrm{MIT} / \mathrm{JPL}$ \\
$54.90 \mathrm{GHz}$ & $0.546 \mathrm{~cm}$ & 1970 & No & $0^{\circ}$ & $10^{\circ}$ & $0.6^{\circ} \mathrm{K}$ & $2 \mathrm{~S}$ & Single \\
$\mathrm{MIT} / \mathrm{JPL}$ \\
$58.80 \mathrm{GHz}$
\end{tabular}


radiometers operating in the $10-12 \mu \mathrm{m}$ window, on both flights. The surface height variation was measured with a nadir pointing Spectra-Physics Model 3A laser Geodolite on the 1970 flight only.

The 1967 flight extended about $100 \mathrm{~km}$ over the ice covered Arctic Ocean north of Pt. Barrow. The 1970 flight ranged over about $800 \mathrm{~km}$ of sea ice north of Pt. Barrow. In both flights, the northbound leg was flown at a height of about $10 \mathrm{~km}$, while a height of less than $150 \mathrm{~m}$ was maintained on the southbound leg, to permit photography and temperature measurements of the water and ice surfaces from underneath a solid stratus cloud deck which extended from 150 to $600 \mathrm{~m}$ above the ice surface during both flights.

\section{RESULTS}

Figure 1 is a false color image of horizontally polarized radiation measured with the $1.55 \mathrm{~cm}$ radiometer over the area indicated in Figure 2. These measurements were made during the northbound leg of the flight and, since the aircraft altitude was $10 \mathrm{~km}$, scan lines are contiguous and cover a swath about 24 kilometers wide. The color scale is such that the areas of highest brightness temperature appear white. Pink, orange, yellow, green, blue, purple and black, relate sequentially, to decreasing brightness temperatures. The absolute calibration of this color scale is neither certain nor constant from picture to picture. Thus, the numerical values of the brightness temperatures presented in this discussion are obtained from the digital records rather than from the color images. Features such as the ice/water boundary off the coast of Point Barrow, the ice covered Elson Lagoon and Iko Bay as well as numerous frozen lakes including a portion of Lake Tusikvoak are clearly recognizable. Brightness temperatures of all the open water areas are uniformly about $120^{\circ} \mathrm{K}$, while brightness temperatures of the sea ice, the frozen lakes and Elson Lagoon are consistently about 250 to $260^{\circ} \mathrm{K}$. Over the more heterogeneous frozen tundra, brightness temperatures varied about $210^{\circ} \mathrm{K}$ to $260^{\circ} \mathrm{K}$. This is much colder than one might expect for such a frozen land surface, but is consistent with the extremely low brightness temperatures, as cold as $120^{\circ} \mathrm{K}$, observed for dry snow in Colorado at a wavelength of $0.81 \mathrm{~cm}$ by Edgerton et al (1968). The extremely cold (black and purple) areas near the edges of Figure 1 are the result of limb darkening, i.e., a decrease in emissivity due to viewing the surface in horizontal polarization at near grazing angles.

Figure 3 shows a $1.55 \mathrm{~cm}$ brightness temperature image obtained about $280 \mathrm{~km}$ north of Point Barrow during the June 11, 1970 flight. The aircraft altitude was only 160 meters so the perspective distortion is quite severe in this image. The image covers an area 380 meters wide by 20 kilometers long. A small polynya was oriented more or less perpendicular to the aircraft flight path and was about 500 meters wide. This polynya appears as a black streak of 
very low brightness temperature $\left(120^{\circ} \mathrm{K}\right)$ across the top of the image. As in Figure 1, the open water of the polynya shows a strong contrast with the ice. The wide range of brightness temperature variations $\left(220-260^{\circ} \mathrm{K}\right)$ which was observed over the tundra in 1967 is also evident in Figure 3, however, in this case the brightness temperature fluctuations appear over the sea ice. This variation of brightness temperatures over the ice maps some significant contrasts which, we believe, relate to the physical properties of the ice surface.

Figure 4 is a montage of the infrared ektachrome photographs of the ice corresponding to two portions of the microwave image in Figure 3 . The left hand strip clearly shows the open water indicated near the top of Figure 3 . In the right hand strip, there is a change of texture from uniform to quite mottled near $23 \mathrm{~h}^{25} \mathrm{~m}_{\mathrm{s}} 2 \mathrm{G}$ (GMT). This change is not to be confused with the gross color change occurring between succeeding photographic frames. It corresponds to the transition from lower (blue/green) to higher (red/yellow) microwave emissivities seen near $23_{\mathrm{h}} 25_{\mathrm{m}} 20_{\mathrm{s}}$ in Figure 3. It appeared from visual observations that both areas are first year ice but that the mottled portion was formed under more dynamic conditions, underwent severe rafting during formation and is presumably younger than the more uniform ice. The scale of alternations of high and low brightness temperatures, observed over much of the 1970 flight, ranged from less than $1 \mathrm{~km}$ to several tens of kilometers along the aircraft track. A very large area, $50 \mathrm{~km}$ long, of low brightness temperatures $\left(220^{\circ} \mathrm{K}\right)$ was observed at about $72^{\circ} 30^{\prime}$ north. A similarly large area of high brightness temperatures $\left(250^{\circ} \mathrm{K}\right)$ was observed near $75^{\circ}$ North and also near the coast of Pt. Barrow.

Figure 5 shows the laser geodolite record for the distance covered along the center of Figure 3. The upper curve of each pair is the uncalibrated intensity of the reflected laser signal which shows strikingly the change between the two types of ice. There are strong variations in reflected laser light intensity for those time intervals when the higher brightness temperatures were observed while there are practically no variations at the times when the lower brightness temperatures were observed. The small polynya of Figure 4 can also be seen as a sharp decrease in the reflected laser light intensity near $23_{\mathrm{h}} 25_{\mathrm{m}}{ }^{19} \mathrm{~s}^{\text {. The }}$ profile of the ice surface shows a more subtle, but nevertheless significant, contrast between the areas of high and low microwave emissivity. Note that the region of low emissivity between $23_{\mathrm{h}} 25_{\mathrm{m}} 10_{\mathrm{s}}$ and $23 \mathrm{~h} 25_{\mathrm{m}} 2 \mathrm{~s}_{\mathrm{s}}$ contains virtually no structure greater than about 0.5 feet $(15 \mathrm{~cm})$ in amplitude, whereas the regions of high emissivity $\left(23_{\mathrm{h}}, 25_{\mathrm{m}} 00_{\mathrm{s}}\right.$ to $23_{\mathrm{h}} 25_{\mathrm{n}} 10_{\mathrm{s}}$ and $23_{\mathrm{h}} 25_{\mathrm{m}} 24_{\mathrm{s}}$ to $\left.23_{\mathrm{h}} 25_{\mathrm{m}} 34_{\mathrm{s}}\right)$ contain numerous ridges of the order 2 to 4 feet $(60$ to $120 \mathrm{~cm})$ in height. However, the region of low emissivity $23_{\mathrm{h}} 24_{\mathrm{m}} 52_{\mathrm{s}}$ to $23_{\mathrm{h}} 25_{\mathrm{m}} 00_{\mathrm{s}}$, to a lesser extent from $23_{\mathrm{h}} 25_{\mathrm{m}} 35_{\mathrm{s}}$ to the end of the laser data in Figure 6 , also contain ridges. Closer examination shows these ridges to be less steep and angular than those of the high emissivity regions. This is interpreted as weathering of the 
ridges and is diagnostic of older ice which is consistent with the more tentative relative age identification made from the photographs. That is, "new" ice has a higher emissivity than "old" ice. The time scale involved is not too clear, but considering that the visual observations indicated both high and low emissivity regions to be first year ice, it is suggested, that ice becomes "old" for microwave purposes in less than one year.

We have attempted to derive emissivities for these two types of ice surfaces at each of the microwave wavelengths at which observations were made with the aircraft in 1970. The calculation of the emissivity, $\epsilon$, of a surface from its radiometric brightness temperature $T_{B}$ depends on knowing its thermodynamic temperature $\mathrm{T}_{\mathrm{O}}$ and the reflected sky radiation $\mathrm{T}_{\mathrm{S}}$ :

$$
\epsilon=\left(\mathrm{T}_{\mathrm{B}}-\mathrm{T}_{\mathrm{S}}\right) /\left(\mathrm{T}_{\mathrm{O}}-\mathrm{T}_{\mathrm{S}}\right)
$$

Brightness temperatures measured over both types of ice surfaces are shown in Figure 6 for all nadir viewing radiometers (upper left) the $0.8 \mathrm{~cm}$ radiometer viewing $45^{\circ}$ left of nadir (upper right) and the corresponding $45^{\circ}$ left of nadir beam position of the $1.55 \mathrm{~cm}$ scanning radiometer (lower right) and the nadir viewing beam position of the $1.55 \mathrm{~cm}$ radiometer (lower left). Note the contrasting brightness temperatures at all wavelengths over "new" and "old" ice surfaces. This contrast is largest at the shortest wavelength $(0.811 \mathrm{~cm})$. At $0.559 \mathrm{~cm}$, the contrast is still apparent, but is difficult to measure because of the large and uncertain atmosphere (sky) radiation component, $\mathrm{T}_{\mathrm{S}}$. The effect was not visible in the other two $0.5 \mathrm{~cm}$ radiometers because they are even nearer the center of the $0.5 \mathrm{~cm}$ molecular oxygen absorption complex and the resulting very large sky radiation component due to atmospheric opacity reduces the effect of changing ice types to well below instrumental noise levels. It is also interesting to note that the increasing contrast in brightness temperature (between the two ice surfaces) with decreasing wavelength is opposite to the ice-water contrast where greater contrasts are observed at the longer wavelengths.

The thermodynamic temperatures of both types of ice surfaces and of the open water were measured at $273^{\circ} \mathrm{K}$ within a $\pm 1^{\circ} \mathrm{C}$ probable error of the infrared (10-12 micron) radiometer. The sky radiation reflected from the surfaces to the aircraft was computed on the basis of a $3^{\circ} \mathrm{K}$ cosmic background (Penzias and Wilson, 1965), emission by atmospheric oxygen (Wilheit 1969), water vapor (Staelin 1966) and clouds. The contribution due to clouds was calculated by the Rayleigh approximation (Gunn and East 1954) using the data of Lane and Saxton (1952) for the dielectric properties of water. In these calculations we assumed atmospheric temperature and water vapor profiles consistent with those measured by the aircraft instruments and four cloud models with liquid water contents ranging from 0 to $3 \times 10^{-2} \mathrm{~cm}$. Because of the small variation of temperature 
with height found in the Arctic atmosphere, the calculations are quite insensitive to the assumed vertical distribution of cloud liquid water content. The zenith brightness temperatures thus calculated are shown in Figure 7. The observed point shown is taken from the $.955 \mathrm{~cm}$ zenith viewing radiometer onboard the aircraft and indicates a cloud water content around $0.015 \mathrm{~cm}$. Measurements with the $3.23 \mathrm{~cm}$ radiometer were also consistent with this value, considering the noise and calibration uncertainty of the radiometer and the very small variation of zenith brightness with liquid water at this wavelength. Assuming 0.015 $\mathrm{cm}$ of liquid water in the clouds, these zenith temperatures were used to compute the amount of sky radiation reflected from the ice surface, assuming a Lambertian (Peake et al. 1966) distribution of brightness:

$$
\mathrm{T}_{\mathbf{S}}=2 \int_{0}^{\pi / 2} \cos (\theta) \sin (\theta) \mathrm{T}_{\mathbf{R}}(\theta) \mathrm{d} \theta
$$

where $T_{R}$ is the sky brightness as a function of zenith angle $\theta$. The resulting reflected sky radiation at the different wavelengths are shown in Table II. Also, in Table II we show the emissivities of open water which were calculated assuming a smooth, specular water surface and using our computed zenith brightness (Figure 7). Calculated brightness temperatures of the water are also shown in Table II. These were compared with the observed brightness temperatures over open water. The $1.55 \mathrm{~cm}, 1.35 \mathrm{~cm}$ and $.955 \mathrm{~cm}$ radiometers each of which had a liquid Nitrogen calibration source showed agreement to within $3^{\circ} \mathrm{K}$ which lends support to the assumptions made in our atmospheric radiation calculations. For the remaining radiometers, which used the less reliable hot source method of calibration, we used the calculated water brightness temperatures to correct the calibrations. The corrections never exceeded $5^{\circ} \mathrm{K}$ in the range of the ice brightness temperatures. We could not use the open water feature shown in Figures 3, 4, and 6 for the comparison shown in Table II, since several of the radiometers had integration times of one second or longer and could not completely resolve this particular feature. Instead, we used a pass over a very wide polynya which occurred about $100 \mathrm{~km}$ south of the one shown in Figures 3 , 4 , and 6 to make this comparison.

The emissivities for the two types of ice surfaces as a function of wavelength are plotted in Figure 8 . We attribute the scatter which is apparent in the plots primarily to residual errors in the absolute calibration of the different radiometers. We have, therefore, plotted the emissivity differences between the "new" and "old" ice to eliminate errors caused by uncertainties in the absolute calibration. Emissivity differences show a nearly linear dependence on wavelength. Emissivity differences observed at $45^{\circ}$ nadir angles $(0.8$ and $1.55 \mathrm{~cm})$ are somewhat less than in the nadir direction indicating that there is less contrast at greater angles of incidence. We have also shown, for comparison, in Figure 8 , the emissivity difference between open water and the "new" ice. It should be noted that the emissivity difference between ice and open water is largest 
Table II

Confirmation of Sky Brightness Model and Radiometer Calibration

\begin{tabular}{|c|c|c|c|c|c|c|c|}
\hline $\begin{array}{c}\text { Wavelength } \\
(\mathrm{cm})\end{array}$ & $\begin{array}{c}\text { Frequency } \\
(\mathrm{GHz})\end{array}$ & $\begin{array}{c}\text { Viewing } \\
\text { Angle } \\
\text { (with respect } \\
\text { to Nadir) }\end{array}$ & $\begin{array}{c}\text { Polari- } \\
\text { zation }\end{array}$ & $\begin{array}{c}\mathrm{T}_{\mathrm{S}} \\
\text { (Calcu- } \\
\text { lated) }\end{array}$ & $\begin{array}{c}\text { Water } \\
\text { (Calcu- } \\
\text { lated) }\end{array}$ & $\begin{array}{c}\mathrm{T}_{\mathrm{B}} \\
\text { Water } \\
\text { (Calcu- } \\
\text { lated) }\end{array}$ \\
\hline 2.81 & 10.69 & $0^{\circ}$ & $8^{\circ} \mathrm{K}$ & .392 & $112^{\circ} \mathrm{K}$ \\
(Observed) \\
1.55
\end{tabular}


observed in horizontally polarized radiation and smallest for vertically polarized radiation (Fig. 7) but emissivity difference between the two types of ice surfaces is about the same for both polarizations. Therefore, mapping of sea ice from satellites should be performed with dual-polarized radiometers, so that small brightness temperature differences which could be caused by icewater contrasts too small to fill the field of view of the antenna can be distinguished against equal brightness temperature differences caused by contrasts in ice types.

\section{CONCLUSIONS}

The strong microwave emissivity contrasts between ice and liquid water surfaces may be used to map, from satellites, polynyas and other open water areas over the polar ice canopies. For typical atmospheric conditions, brightness temperatures over open water are $55 \%$ and $40 \%$ lower than those over ice at $3 \mathrm{~cm}$ and $1.0 \mathrm{~cm}$ wavelengths respectively.

In addition, the ice surface appears to fall into two categories, one with a higher microwave emissivity than the other. We have tentatively identified the more emissive ice as "new" and the less emissive as "old." The division between "old" and "new" appears to be of the order of months. There was very little ice of an intermediate nature observed. The contrast in emissivity between the two ice types is as much as $25 \%$ near $1 \mathrm{~cm}$ wavelength. We conclude that the optimum wavelength for observing both the ice/water and the ice type contrasts from satellites is near $1 \mathrm{~cm}$, because the strongest contrast between different ice surface types exists at this wavelength, while the contrast between ice and open water is still strong enough to be mapped with a wide margin in signal to noise ratio. Furthermore, higher spatial resolutions can be achieved at $1 \mathrm{~cm}$ than at longer wavelengths. From spacecraft orbiting at heights of about $1000 \mathrm{~km}$ with reasonably sized antennas $\left(1\right.$ meter $\left.^{2}\right) 10-20 \mathrm{~km}$ spatial resolutions will result.

Surveys of polar sea ice, even with the coarse spatial resolution to which near term spaceborne radiometers will be limited, will be useful to a variety of scientific investigations and to practical applications. Measurements and maps of the distribution of sea ice in polar regions, such as those described above, when made globally and periodically, could provide an assessment of the amount and distribution of heat energy stored in the polar regions and available to drive atmospheric circulation. They could also provide large scale synoptic data needed to test numerical models of the dynamics of the ice canopy and ocean. Such maps would also be of some use for the routing of ships in Arctic. 


\section{REFERENCES}

1. Badgley, F. I., Heat Budget at the Surface of the Arctic Ocean, (1966). Proceedings of the Symposium on the Arctic Heat Budget and Atmospheric Circulation, edited by J. O. Fletcher, The Rand Corporation (RM-5233-NSF).

2. Edgerton, A. T., R. M. Mandl, G. A. Poe, J. E. Jenkins, F. Soltis and S. Sakamoto. (1968). Passive Microwave Measurements of Snow, Soils, and Snow-Ice-Water Systems. Technical Report No. 4, SGD 829-6. Aerojet General Corp., Space Division, El Monte, Calif.

3. Gunn, K. L. S. and T. W. R. East, (1954). The Microwave Properties of Precipitation Particles. Quart. J. Met. Soc., 80, 522-545.

4. Lane, J. A. and J. A. Saxton, (1952). Dielectric Dispersion in Pure Polar Liquids at Very High Radio Frequencies. Proc. Roy. Soc., A 213, pp. 400-408.

5. Oister, G. and C. V. Falco (1967). Microwave Radiometer Design and Development. Final Report, Contract NAS5-9680, Aerojet General Corp., Space Division, El Monte, Calif.

6. Peake, W. H., R. L. Riegler and C. A. Schultz (1966). The Mutual Interpretation of Active and Passive Microwave Sensor Outputs. Proc. 4th Symp. On Remote Sensing of Environment. Univ. of Mich., Ann Arbor.

7. Penzias, A. A. and R. W. Wilson (1965). A Measurement of Excess Antenna Temperature at $4080 \mathrm{mc} / \mathrm{s}$. Astrophysical Journal, 142, pp. 419-421.

8. Rosenkranz, P. W., D. H. Staelin, F. T. Barath, J. C. Blinn, and E. J. Johnston (1971). Indirect Sensing of Atmospheric Temperature and Water Vapor Using Microwaves. Proc. 7th Symp. on Remote Sensing of Environment. Univ. of Mich., Ann Arbor.

9. Staelin, D. H. (1966). Measurements and Interpretation of the Microwave Spectrum of the Terrestrial Atmosphere near 1 Centimeter Wavelengths. J. Geophys. Res., 71, pp. 2857-2881.

10. Wilheit, T. T. (1969). Microwave Emission and Absorption by Atmospheric Oxygen. (Ph.D. Thesis, Massachusetts Institute of Technology, Cambridge).

11. Wittmann, W. and J. Schule (1966). Comments on the Mass Budget of Arctic Pack Ice. Proc. Symp. on the Arctic Heat Budget and Atmospheric Circulation, edited by J. O. Fletcher. The Rand Corp. (RM-5233-NSF). 
Figure 1. False color $1.55 \mathrm{~cm}$ Microwave Image of Barrow, Alaska area. 


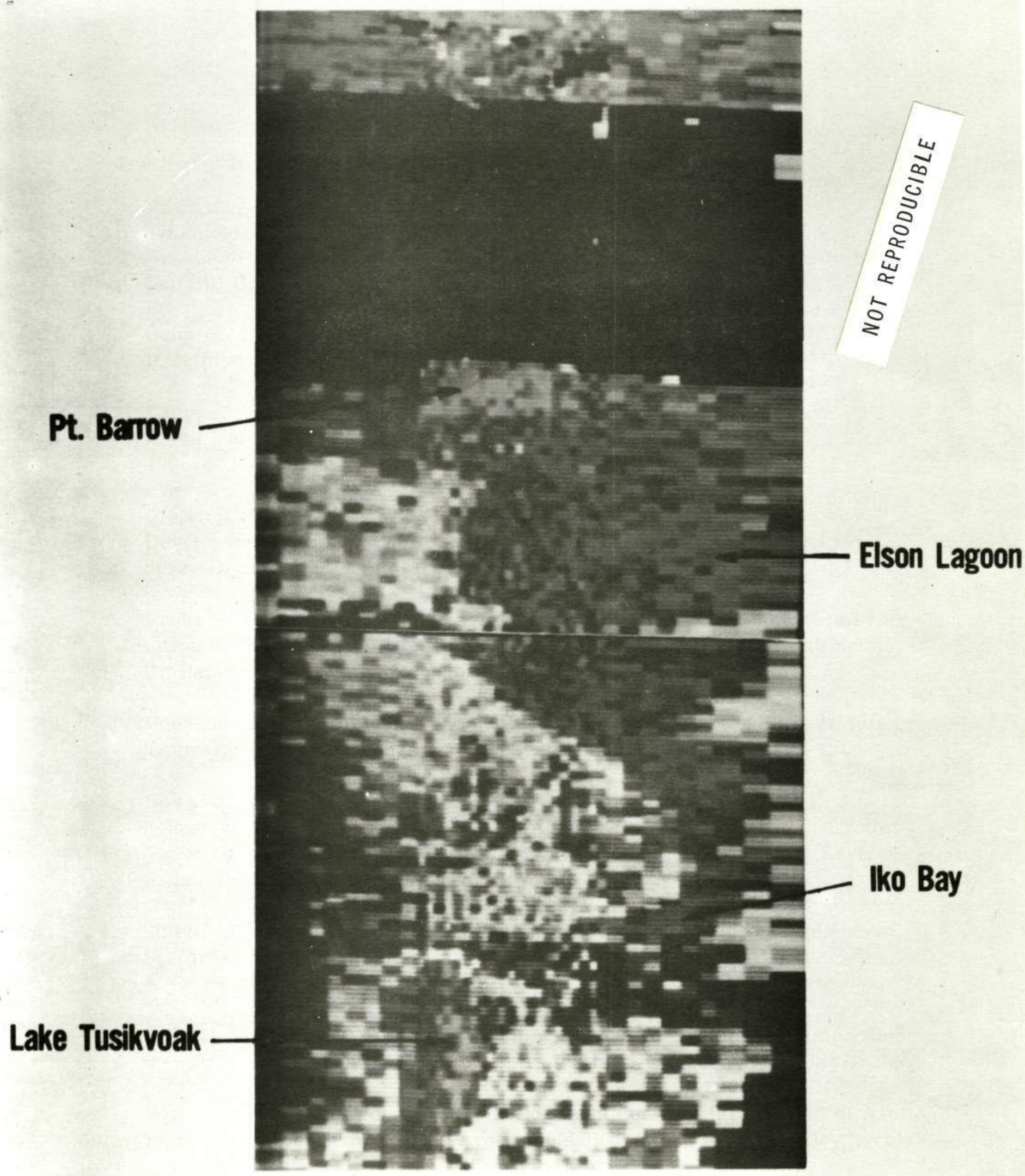


PRECEDING PAGE BLANK NOT FILMED

Figure 2. Map of a portion of the 1967 flight path. 


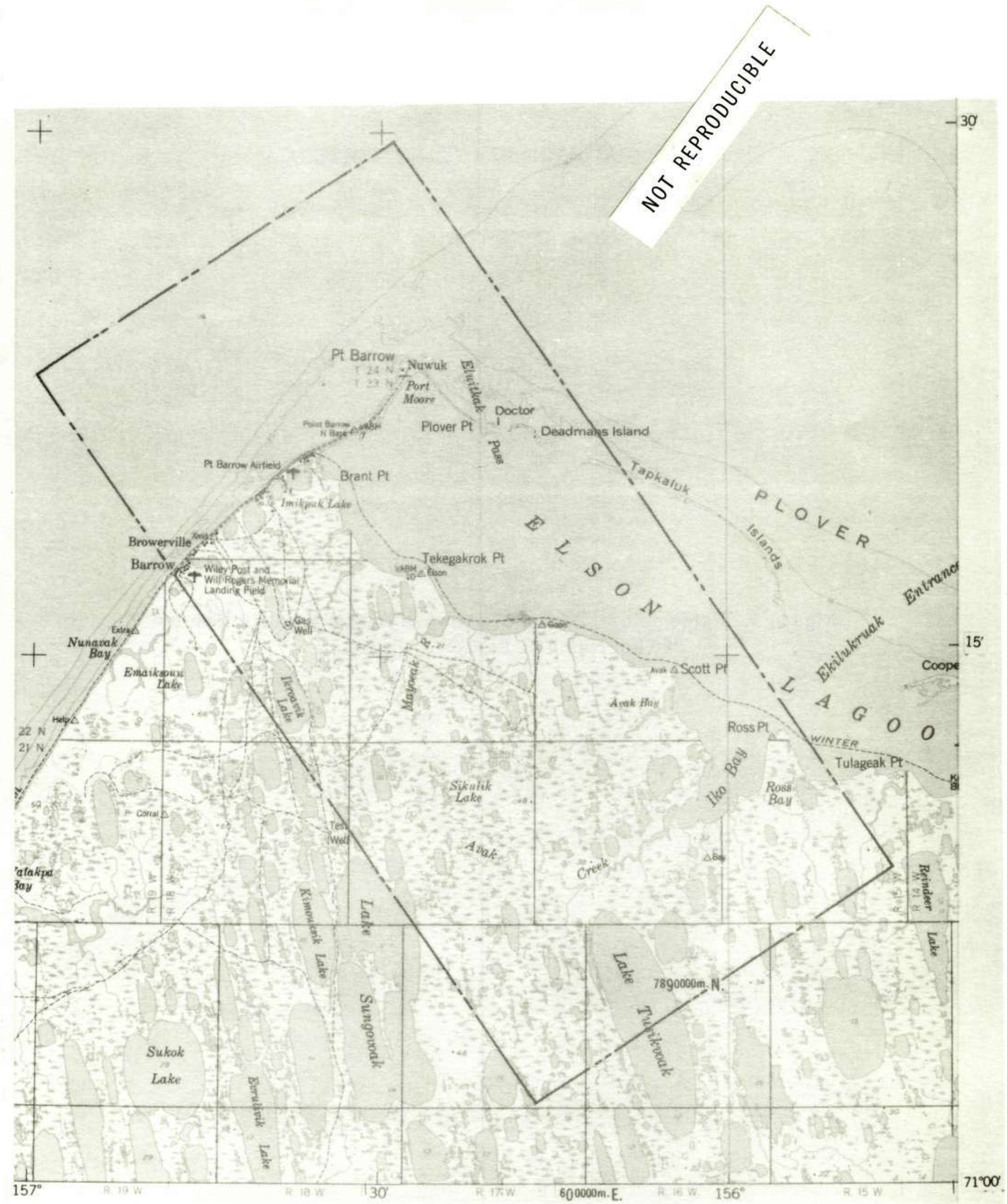


PRECEDING PAGE BLANK NOT FILMED

Figure 3. False color $1.55 \mathrm{~cm}$ Microwave Image of Arctic Sea Ice $280 \mathrm{~km}$ North of Barrow, Alaska. 


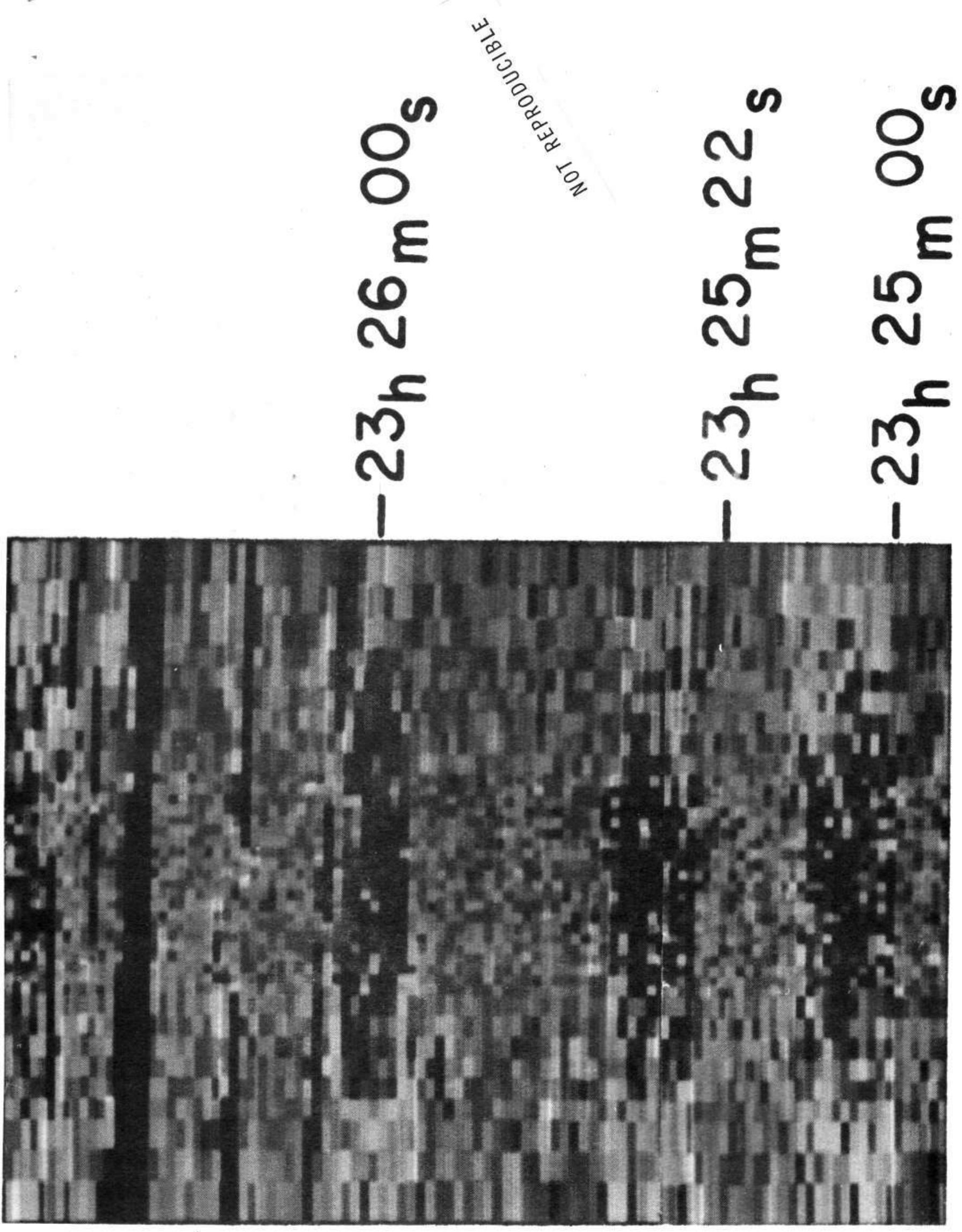




\section{QRECHING PAGE BLANK NOT FILMED}

Figure 4. Infrared ektrachrome photomosaic of Arctic Sea Ice $280 \mathrm{~km}$ North of Barrow, Alaska. 


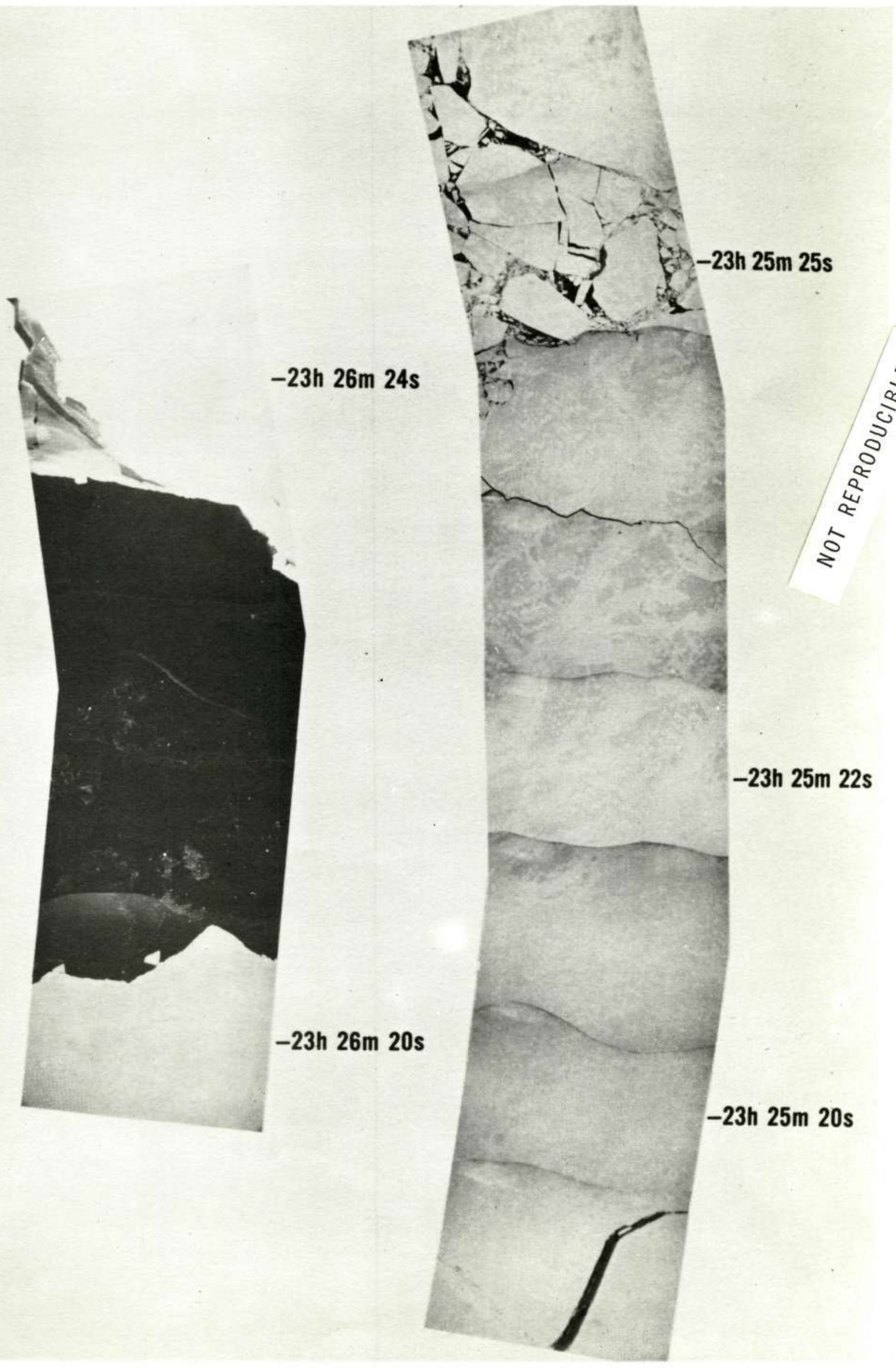



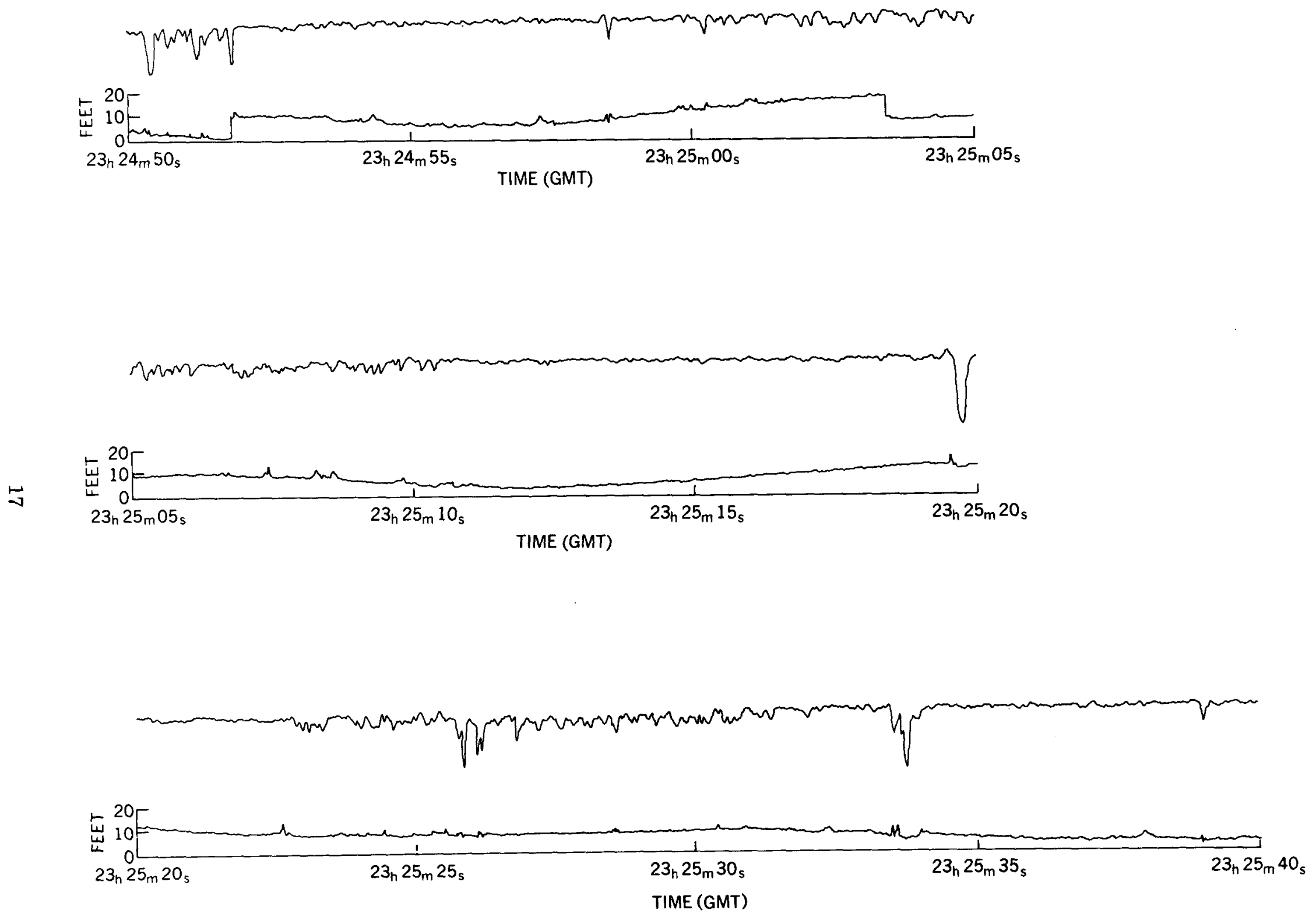

Figure 5. J.aser geodolite profile of Arctic Sea Ice $280 \mathrm{~km}$ North of Barrow, Alaska. 

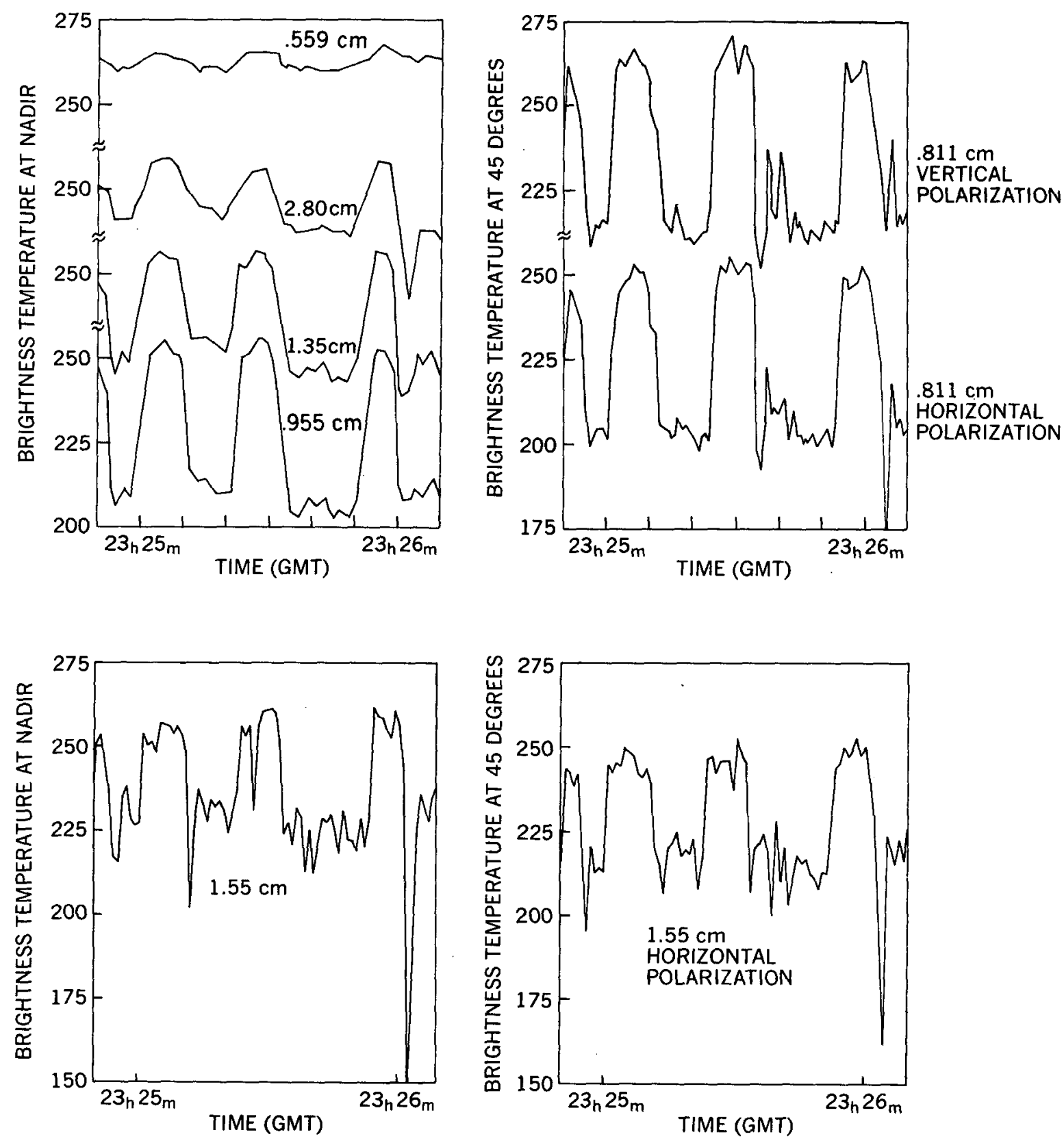

Figure 6. Microwave brightness temperature record for Arctic Sea Ice $280 \mathrm{~km}$ North of Barrow, Alaska. 


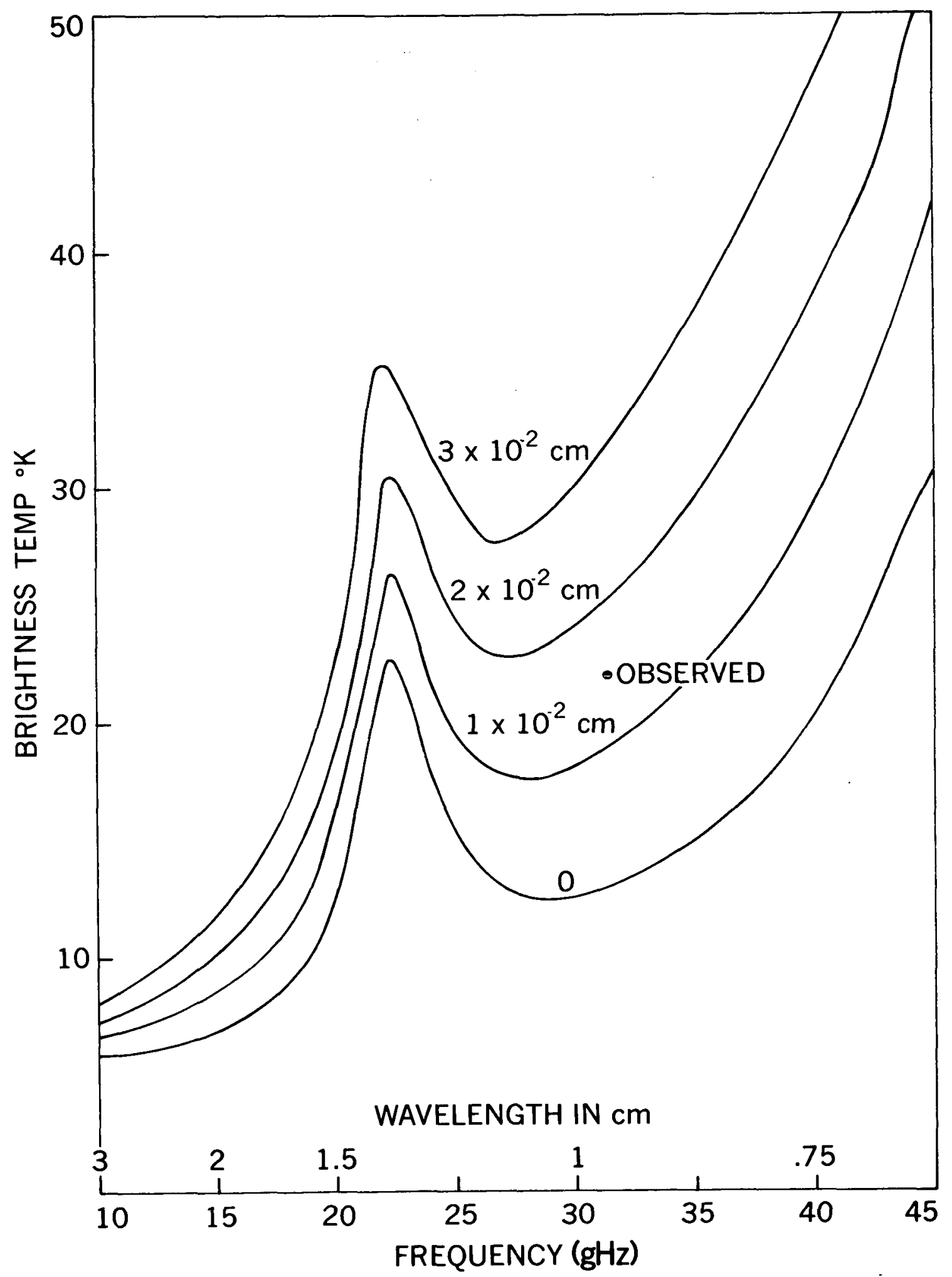

Figure 7. Calculated zenith brightness temperature for four different cloud models with indicated liquid water content. 


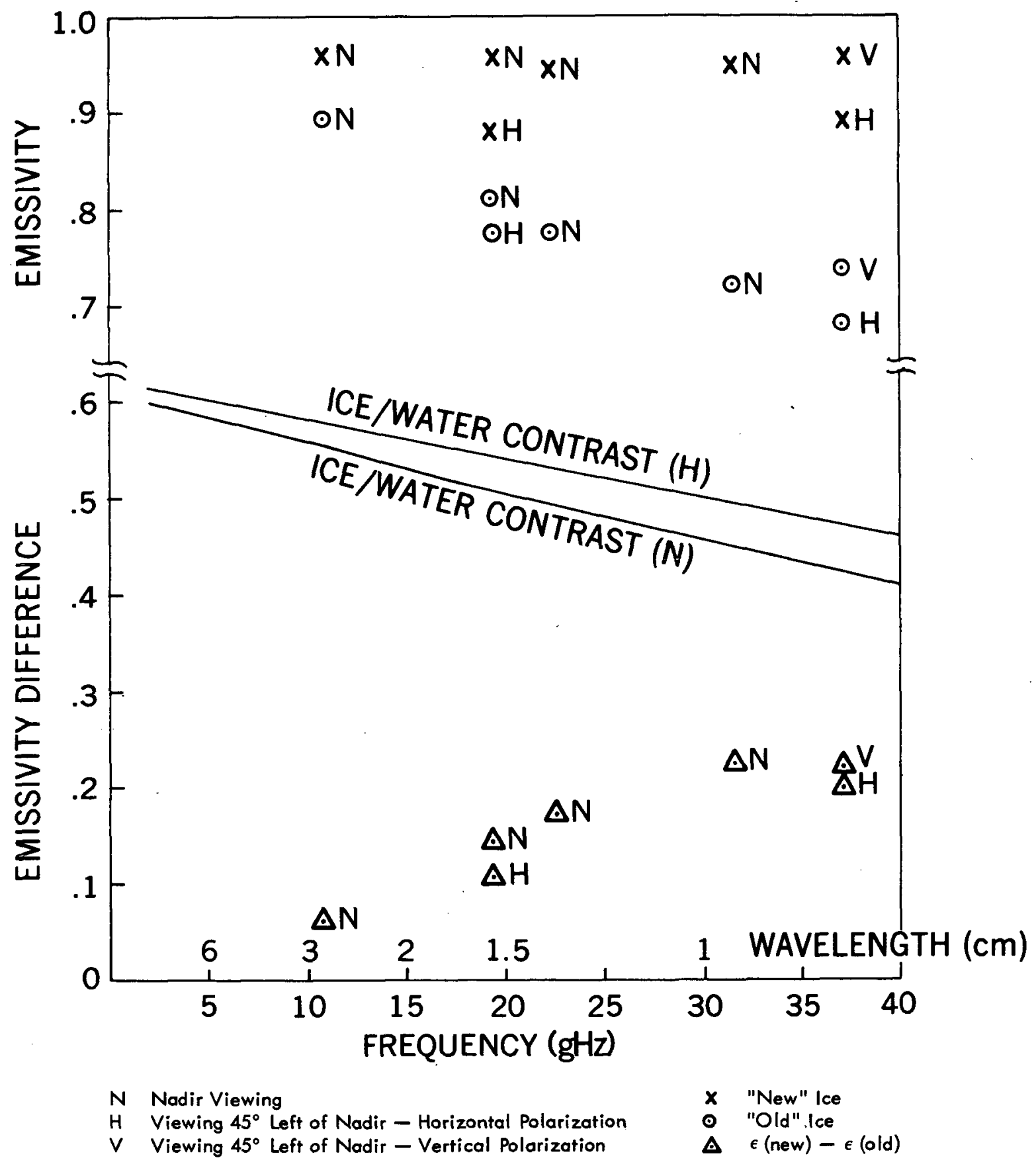

Figure 8. Observed emissivity spectrum of "old" and "new" ice. 